\title{
Restaurant Tipping and Economic Efficiency in the Restaurant Market: An Economic Theoretical Analysis
}

\author{
Tin-Chun Lin \\ School of Business and Economics, Indiana University-Northwest, Gary, IN, USA \\ Email: tinlin@iu.edu
}

How to cite this paper: Lin, T.-C. (2020). Restaurant Tipping and Economic Efficiency in the Restaurant Market: An Economic Theoretical Analysis. Theoretical Economics Letters, 10, 1136-1145. https://doi.org/10.4236/tel.2020.105067

Received: September 7, 2020

Accepted: October 24, 2020

Published: October 27, 2020

Copyright $\odot 2020$ by author(s) and Scientific Research Publishing Inc. This work is licensed under the Creative Commons Attribution International License (CC BY 4.0).

http://creativecommons.org/licenses/by/4.0/

Open Access

\begin{abstract}
In this research, we investigated an interesting and important issue: whether restaurant tipping would lead to economic efficiency or inefficiency in the restaurant market. We applied the theory of consumer choice to link restaurant tipping and consumer behavior. According to our economic theoretical analysis, we concluded that restaurant tipping does discourage consumer demand for restaurant meals, and hence leads to a substitution effect. The presence of a substitution means that well-being has been lost due to the substitution effect of a price-distorting tip, resulting in economic inefficiency in the restaurant market.
\end{abstract}

\section{Keywords}

Restaurant Tipping, Economic Efficiency, Economic Inefficiency, Deadweight Loss

\section{Introduction}

Numerous previous studies related to restaurant tipping have mainly focused on the consumer behavior of restaurant tipping. Questions include: why do diners tip, do diners tip a fixed percentage of the bill size, do frequent diners tip more than infrequent diners for the same quantity of service, and what determinants would motivate diners to tip? These related studies mostly have been undertaken by applied social psychologists and economists (e.g., Freeman, Borden, \& Latane, 1975; Lynn \& Latane, 1984; Lynn, 1988; Lynn \& Grassman, 1990; Bodvarsson \& Gibson, 1994; May, 1978; Crusco \& Wetzel, 1984; Lin, 2007; Lynn, 2018; Lin, 2015).

While a fair number of previous studies have significantly contributed to the 
area of restaurant tipping, the issue of economic efficiency has not been broadly investigated and discussed. That is, researchers have not looked at how the economic activity of restaurant tipping influences consumers' behavior in demanding restaurant meals and hence affects economic efficiency in the restaurant market.

For that reason, in this paper, we focus on the issue of economic efficiency in the area of restaurant tipping. Our economic theoretical analysis centered on answering one question: whether restaurant tipping would lead to economic efficiency or inefficiency in the restaurant market?

\section{The Simple Model}

\subsection{The Utility Function}

To investigate this issue, we applied the theory of consumer choice in developing a simple model that connects consumer behavior and restaurant tipping. We assumed that a consumer always consumes two goods weekly: restaurant meals (denoted by $R$, which also indicates the quantity of restaurant meals) and grocery foods (denoted by $G$, which also indicates the quantity of grocery foods). The reason of introducing grocery foods in the model is that restaurant meals and grocery foods are substitutes. We either dine-out at restaurants or dine-in at home. If we dine-in at home, we need to purchase foods from grocery stores. In addition, we assumed that the consumer enjoys the servers' services, so the consumer always dines at a restaurant that provides servers' services. For that reason, we did not include fast-food restaurants, such as Burger King, McDonald's, etc., in this study because fast-food restaurants do not offer server services and therefore tipping is not an issue.

We assumed that every consumer maximizes their utility. Following the parameters of the case involved in this study, the consumer can be satisfied by dining at a restaurant and shopping at a grocery store; thus, the consumer's utility function consists of restaurant meals $(R)$, grocery foods $(G)$, and the external factors that may affect the consumer's utility (denoted by $A$ ), such as weather. The quantities of restaurant meals $(R)$ and grocery foods $(G)$ are factors that can be determined by the consumer; hence, these two factors are variables. However, the external factors that may affect the consumer's utility $(A)$ are factors that cannot be determined by the consumer, so these factors are constant terms. To simplify the model, we assumed that the consumer's utility function displays the Cobb-Douglas form, which can be expressed as:

$$
U(A ; R, G)=A R^{\alpha} G^{\beta},
$$

where $\alpha$ and $\beta$ are constant parameters and shares of restaurant meals $(R)$ and grocery foods $(G) ; U_{R}, U_{G}>0 ; U_{R R}, U_{G G}<0$; and $U_{R R}=U_{G G}>0$.

\subsection{The Budget Constraint Line}

Suppose that the initial price of one restaurant meal without sales taxes and res- 
taurant tipping is $P_{R_{0}}$. However, sales taxes are charged on restaurant meals. Thus, including sales taxes (suppose that the sales tax rate is $\tau$ ), the consumer pays $P_{R_{1}}=(1+\tau) P_{R_{0}}$ for one restaurant meal. Moreover, although restaurant tipping is voluntary, the consumer's behavior is guided by social norms and hence pays a tip in order to guarantee social approval. As a result, including sales taxes and restaurant tipping (assume that the tipping rate is $t$ ), the consumer eventually pays $P_{R_{2}}=(1+t)\left[(1+\tau) P_{R_{0}}\right]$ for one restaurant meal.

In addition, 32 states and the District of Columbia in the United States exempt groceries from their sales tax base (only 18 states do not exempt groceries from their sales tax base). The main goal of this study is to investigate how restaurant tipping affects economic efficiency in the restaurant market rather than in the grocery market. For that reason and to simplify the model, we assume that the state government does not levy sales taxes on grocery foods. We believe that our assumption is proper for this study. Therefore, the consumer pays only the price of the food (denoted by $P_{G}$ ) when the consumer shops at a grocery store.

Moreover, we assume that the consumer's total weekly budget for these two goods is $M$, and that the consumer will spend precisely this budget $(M)$ on these two goods ( $R$ and $G$ ) weekly. Consequently, the consumer's budget constraint line can be displayed as follows:

$$
(1+t)(1+\tau) P_{R_{0}} \cdot R+P_{G} \cdot G=(1+\tau+t+t \tau) P_{R_{0}} \cdot R+P_{G} \cdot G=M .
$$

\subsection{Equilibrium}

To solve the consumer's optimization problem, we can maximize Equation (1) subject to Equation (2) and choose $R$ and $G$. Therefore, the Lagrangian expression can be shown as follows:

$$
L=A R^{\alpha} G^{\beta}+\lambda\left[M-(1+\tau+t+t \tau) P_{R_{0}} \cdot R-P_{G} \cdot G\right]
$$

where $\lambda$ stands for the Lagrangian multiplier or a shadow price. According to the Lagrangian expression (Equation (3)), we solve the first-order conditions for the constrained maximum:

$$
\begin{aligned}
& \frac{\alpha A R^{\alpha-1} G^{\beta}}{(1+\tau+t+t \tau) P_{R_{0}}}=\frac{\beta A R^{\alpha} G^{\beta-1}}{P_{G}} \\
& M=(1+\tau+t+t \tau) P_{R_{0}} R+P_{G} G
\end{aligned}
$$

Based upon Equations (4) and (5), we can solve the equilibriums of these two goods:

$$
R^{*}=\frac{\alpha}{\alpha+\beta} \cdot \frac{1}{1+\tau+t+t \tau} \cdot \frac{M}{P_{R_{0}}}=R\left(\bar{\tau}, \bar{t}, \overline{P_{R_{0}}}, \stackrel{+}{M}\right),
$$

and

$$
G^{*}=\frac{\beta}{\alpha+\beta} \cdot \frac{M}{P_{G}}=G\left(\stackrel{-}{P_{G}}, \stackrel{+}{M}\right)
$$

We then plug $R^{*}$ and $G^{*}$ into the utility function $(U)$, Equation (1), which can be 
solved as:

$$
\begin{aligned}
U^{*} & =A\left(\frac{\alpha}{\alpha+\beta}\right)^{\alpha}\left(\frac{\beta}{\alpha+\beta}\right)^{\beta}\left(\frac{M}{P_{R_{0}}}\right)^{\alpha}\left(\frac{M}{P_{G}}\right)^{\beta}\left(\frac{1}{1+\tau+t+\tau t}\right)^{\alpha} \\
& =U\left(\stackrel{+}{A}, \stackrel{+}{M}, \overline{P_{R_{0}}}, \overline{P_{G}}, \bar{\tau}, \bar{t}\right)
\end{aligned}
$$

As shown above, the consumer chooses his or her optimal combination of restaurant meals and grocery foods $\left(R^{*}\right.$ and $\left.G^{*}\right)$ to maximize his or her utility at the $U^{*}$ level. Therefore, equilibrium for the restaurant meal $\left(R^{*}\right)$ is related to the price of the restaurant meal $\left(P_{R_{0}}\right)$, sales tax rate $(\tau)$, tipping rate $(t)$, and total budget $(M)$; while equilibrium for the grocery foods $(G)$ is related to the price of the grocery foods $\left(P_{G}\right)$ and total budget $(M)$. In addition, a consumer's equilibrium utility $\left(U^{*}\right)$ is related to the external factor $(A)$, price of the restaurant meal $\left(P_{R_{0}}\right)$, price of the grocery foods $\left(P_{G}\right)$, sales tax rate $(\tau)$, tipping rate $(t)$, and total budget $(M)$.

\subsection{Comparative Static Analysis}

In this subsection, we show the comparative static analysis. First, we further totally differentiate Equations (4) and (5) and obtain:

$$
\begin{gathered}
{\left[\begin{array}{ccc}
U_{R R} P_{G}-U_{G R}(1+t+\tau+t \tau) P_{R_{0}} & U_{R G} P_{G}-U_{G G} P_{R_{0}}(1+t+\tau+t \tau) \\
(1+t+\tau+t \tau) P_{R_{0}} & P_{G}
\end{array}\right]\left[\begin{array}{c}
\mathrm{d} R \\
\mathrm{~d} G
\end{array}\right]} \\
=\left[\begin{array}{ccccc}
0 & U_{G}(1+t+\tau+t \tau) & -U_{R} & U_{G} P_{R_{0}}(1+t) & U_{G} P_{R_{0}}(1+\tau) \\
1 & -(1+t+\tau+t \tau) R & -G & -(1+t) P_{R_{0}} R & -(1+\tau) P_{R_{0}} R
\end{array}\right]\left[\begin{array}{c}
\mathrm{d} M \\
\mathrm{~d} P_{R_{0}} \\
\mathrm{~d} P_{G} \\
\mathrm{~d} \tau \\
\mathrm{d} t
\end{array}\right]
\end{gathered}
$$

where $U_{R}=A \alpha R^{\alpha-1} G^{\beta}>0$,

$$
\begin{aligned}
& U_{R R}=A \alpha(\alpha-1) R^{\alpha-2} G^{\beta}<0, \\
& U_{R G}=U_{G R}=A \alpha \beta R^{\alpha-1} G^{\beta-1}>0, \\
& U_{G}=A \beta R^{\alpha} G^{\beta-1}>0, \text { and } \\
& U_{G G}=A \beta(\beta-1) R^{\alpha} G^{\beta-2}<0 .
\end{aligned}
$$

Let $|D|$ be the determinant of the pre-multiplied matrix of vector $\left[\begin{array}{ll}\mathrm{d} X & \mathrm{~d} Y\end{array}\right]$, which is:

$$
\begin{aligned}
|D| & =\left|\begin{array}{cc}
P_{G} U_{R R}-P_{R_{0}}(1+t+\tau+t \tau) U_{G R} & P_{G} U_{R G}-P_{R_{0}}(1+t+\tau+t \tau) U_{G G} \\
P_{R_{0}}(1+t+\tau+t \tau) & P_{G}
\end{array}\right| \\
& =\left|\begin{array}{ll}
- & + \\
+ & +
\end{array}\right|<0
\end{aligned}
$$

Second, using Cramer's rule, the straightforward comparative static analysis yields: 
$\frac{\mathrm{d} R}{\mathrm{~d} M}=\frac{\left|\begin{array}{cc}0 & U_{R G} P_{G}-U_{G G} P_{R_{0}}(1+\tau+t+t \tau) \\ 1 & P_{y}\end{array}\right|}{|D|}>0$,

$\frac{\mathrm{d} G}{\mathrm{~d} M}=\frac{\left|\begin{array}{cc}U_{R R} P_{G}-U_{G R}(1+\tau+t+t \tau) P_{R_{0}} & 0 \\ (1+\tau+t+t \tau) P_{R_{0}} & 1\end{array}\right|}{|D|}>0$,

$\frac{\mathrm{d} R}{\mathrm{~d} P_{R_{0}}}=\frac{\left|\begin{array}{cc}U_{G}(1+\tau+t+t \tau) & U_{R G} P_{G}-U_{G G} P_{R_{0}}(1+\tau+t+t \tau) \\ -(1+\tau+t+t \tau) R & P_{G}\end{array}\right|}{|D|}<0$,

$\frac{\mathrm{d} G}{\mathrm{~d} P_{R_{0}}}=\frac{\left|\begin{array}{cc}U_{R R} P_{G}-U_{G R}(1+\tau+t+t \tau) P_{R_{0}} & U_{G}(1+\tau+t+t \tau) \\ (1+\tau+t+t \tau) P_{R_{0}} & -(1+\tau+t+t \tau) R\end{array}\right|}{|D|}>$ or $<0$,

$\frac{\mathrm{d} R}{\mathrm{~d} P_{G}}=\frac{\left|\begin{array}{cc}-U_{R} & U_{R G} P_{G}-U_{G G} P_{R_{0}}(1+\tau+t+t \tau) \\ -G & P_{G}\end{array}\right|}{|D|}>$ or $<0$,

$\frac{\mathrm{d} G}{\mathrm{~d} P_{G}}=\frac{\left|\begin{array}{cc}U_{R R} P_{G}-U_{G R}(1+\tau+t+t \tau) P_{R_{0}} & -U_{R} \\ (1+\tau+t+t \tau) P_{R_{0}} & -G\end{array}\right|}{|D|}<0$

$\frac{\mathrm{d} R}{\mathrm{~d} \tau}=\frac{\left|\begin{array}{cc}U_{G} P_{R_{0}}(1+t) & U_{R G} P_{G}-U_{G G} P_{R_{0}}(1+\tau+t+t \tau) \\ -(1+t) P_{R_{0}} R & P_{G}\end{array}\right|}{|D|}<0$,

$\frac{\mathrm{d} G}{\mathrm{~d} \tau}=\frac{\left|\begin{array}{cc}U_{R R} P_{G}-U_{G R}(1+\tau+t+t \tau) P_{R_{0}} & U_{G} P_{R_{0}}(1+t) \\ (1+\tau+t+t \tau) P_{R_{0}} & -(1+t) P_{R_{0}} R\end{array}\right|}{|D|}>$ or $<0$,

$\frac{\mathrm{d} R}{\mathrm{~d} t}=\frac{\left|\begin{array}{cc}U_{G} P_{R_{0}}(1+\tau) & U_{R G} P_{G}-U_{G G} P_{R_{0}}(1+\tau+t+t \tau) \\ -(1+\tau) P_{R_{0}} R & P_{G}\end{array}\right|}{|D|}<0$,

and

$$
\frac{\mathrm{d} G}{\mathrm{~d} t}=\frac{\left|\begin{array}{cc}
U_{R R} P_{G}-U_{G R}(1+\tau+t+t \tau) P_{R_{0}} & U_{G} P_{R_{0}}(1+\tau) \\
(1+\tau+t+t \tau) P_{R_{0}} & -(1+\tau) P_{R_{0}} R
\end{array}\right|}{|D|}>\text { or }<0 .
$$

As reported in Equations (12) and (13), an increase in the price of the restaurant meal deters a consumer's demand for restaurant meals but does not offer concordant knowledge about grocery foods. Similarly, as presented in Equations (14) and (15), a rise in the price of grocery food lessens demand for them and adds to unsure about restaurant meals. Moreover, as displayed in Equations (10) 
and (11), a rise in the consumer's maximum budget enlarges demands for both restaurant meals and grocery foods. Finally, as demonstrated in Equations (16), (17), (18), and (19), an increase in the sales tax rate and tipping rate discourages a consumer's demand for restaurant meals but does not provide consistent information about grocery foods.

\section{Economic Efficiency Analysis}

Equation (6) reflects an equilibrium for restaurant meals-that is, the consumer's demand function of restaurant meals-while Equation (8) is the consumer's utility function. There are three cases of consumer demand function and consumer utility function.

Case 1: There are no sales taxes and tips

If there are no sales taxes and tips, the consumer's demand function for restaurant meals $\left(D_{0}\right)$ is shown as:

$$
R=\frac{\alpha}{\alpha+\beta} \frac{M}{P_{R_{0}}} \Rightarrow P_{R_{0}}=\left(\frac{\alpha}{\alpha+\beta}\right)\left(\frac{M}{R}\right),
$$

while the consumer's utility function $\left(U_{0}\right)$ is shown as below:

$$
U_{0}=A\left(\frac{\alpha}{\alpha+\beta}\right)^{\alpha}\left(\frac{\beta}{\alpha+\beta}\right)^{\beta}\left(\frac{M}{P_{R_{0}}}\right)^{\alpha}\left(\frac{M}{P_{G}}\right)^{\beta}
$$

Graphically, Equations (20) and (21) can be displayed by $D_{0}$ and $U_{0}$, respectively, in Figure 1.

Case 2: There are no tips, but there are sales taxes

If there are no tips but there are taxes, the consumer's demand function for restaurant meals $\left(D_{1}\right)$ is shown as:

$$
R=\frac{\alpha}{\alpha+\beta} \frac{1}{1+\tau} \frac{M}{P_{R_{0}}} \Rightarrow P_{R_{1}}=\left(\frac{\alpha}{\alpha+\beta}\right)\left(\frac{1}{1+\tau}\right)\left(\frac{M}{R}\right)=\frac{P_{R_{0}}}{1+\tau},
$$

while the consumer's utility function $\left(U_{0}\right)$ is shown as:

$$
U_{1}=A\left(\frac{\alpha}{\alpha+\beta}\right)^{\alpha}\left(\frac{\beta}{\alpha+\beta}\right)^{\beta}\left(\frac{M}{P_{R_{0}}}\right)^{\alpha}\left(\frac{M}{P_{G}}\right)^{\beta}\left(\frac{1}{1+\tau}\right)^{\alpha}
$$

Graphically, Equations (22) and (23) can be displayed by $D_{1}$ and $U_{1}$, respectively, in Figure 1. As displayed in Figure 1, the consumer's utility reduces from $U_{0}$ (shown in Equation [21]) to $U_{1}$ (shown in Equation [23]) due to an increase in the final payment on restaurant meals resulting from the sales taxes that create a substitution effect. This is because the grocery foods now become relatively cheaper when there are sales taxes levied on restaurant meals. As Figure 1 shows, when the consumer wants to maintain his/her initial utility at the level of $U_{0}$ (move along the indifference curve, $U_{0}$, from point $h$ to point $i$ ), the consumer will be willing to substitute more units of grocery foods (increase from $G_{0}$ to $G_{1}$ ) for restaurant meals (decrease from $R_{0}$ to $R_{3}$ ). Therefore, the substitution effect is created due to the existence of the sales taxes. 


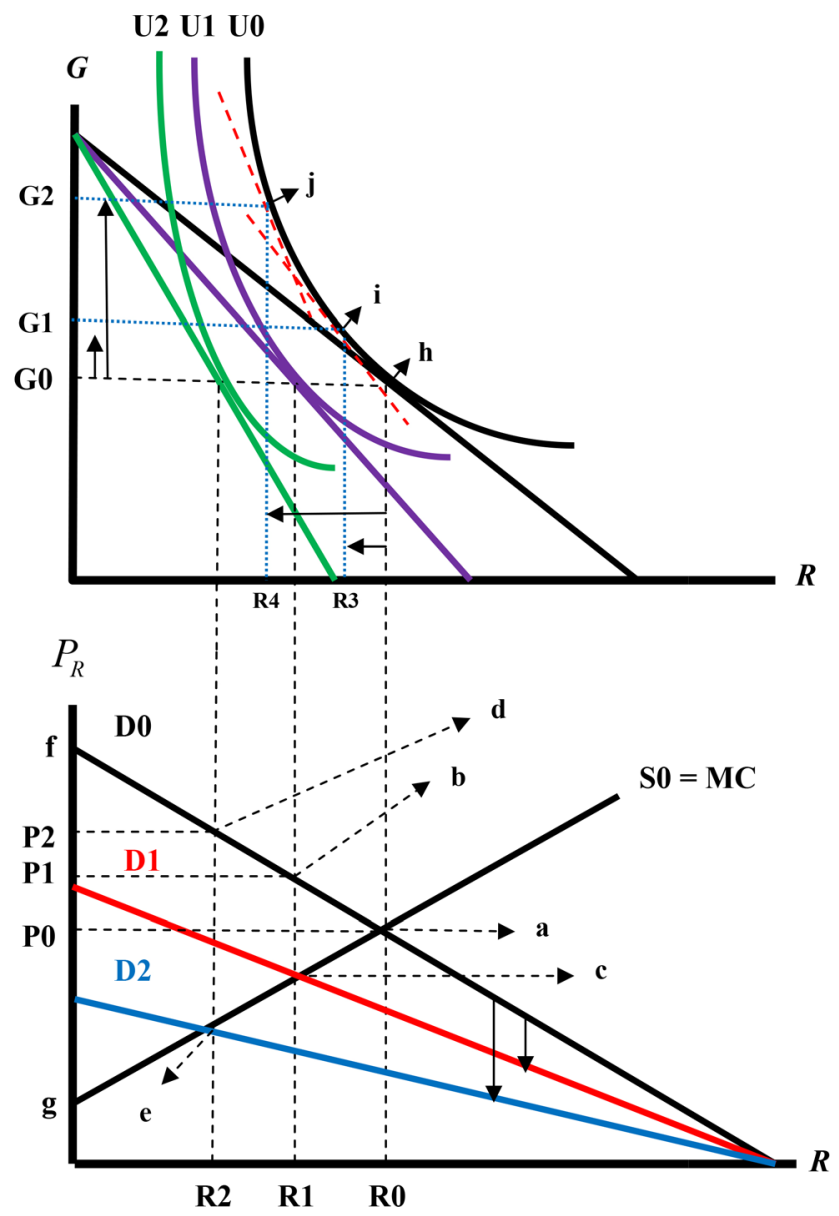

Figure 1. Indifference and demand-supply curves.

Case 3: There are both sales taxes and tips.

If there are both sales taxes and tips, the consumer's demand function for restaurant meals $\left(D_{2}\right)$ is shown as:

$$
\begin{aligned}
& R=\frac{\alpha}{\alpha+\beta} \frac{1}{(1+\tau)(1+t)} \frac{M}{P_{R_{0}}} \\
& \Rightarrow P_{R_{2}}=\left(\frac{\alpha}{\alpha+\beta}\right)\left(\frac{1}{(1+\tau)(1+t)}\right)\left(\frac{M}{R}\right)=\frac{P_{R_{0}}}{(1+\tau)(1+t)}
\end{aligned}
$$

while the consumer's utility function $\left(U_{2}\right)$ is shown as:

$$
U_{2}=A\left(\frac{\alpha}{\alpha+\beta}\right)^{\alpha}\left(\frac{\beta}{\alpha+\beta}\right)^{\beta}\left(\frac{M}{P_{R_{0}}}\right)^{\alpha}\left(\frac{M}{P_{G}}\right)^{\beta}\left(\frac{1}{(1+\tau)(1+t)}\right)^{\alpha}
$$

Graphically, Equations (24) and (25) can be displayed by $D_{2}$ and $U_{2}$, respectively, in Figure 1. Again, as Figure 1 demonstrates, the consumer's utility reduces from $U_{0}$ (displayed in Equation [21]) to $U_{2}$ (displayed in Equation [25]) due to an augment in the final payment on restaurant meals arising from both sales taxes and restaurant tipping that create a substitution effect. As explained above, similarly, when sales taxes are levied on restaurant meals and consumers tip 
servers, the grocery foods now become relatively less expensive. As Figure 1 exhibits, when the consumer wishes to retain his/her initial utility at the level of $U_{0}$ (move along the indifference curve, $U_{0}$, from point $h$ to point $j$ ), the consumer will be willing to substitute more units of grocery foods (increase from $G_{0}$ to $G_{2}$ ) for restaurant meals (decrease from $R_{0}$ to $R_{4}$ ). As a result, the substitution effect is created in consequence of the presence of the sales taxes and restaurant tipping, and the effect is even bigger than the previous substitution effect when sales taxes exist only without restaurant tipping. For that reason, we believe that restaurant tipping does create a substitution effect as well.

In addition, as Figure 1 shows, the supply curve $\left(S_{0}\right)$ indeed is the seller's marginal cost curve. Lacking sales taxes and tips, when the market is at equilibrium: Demand = Supply, the yield is:

$$
D_{0}=S_{0} \Rightarrow P_{R_{0}}=M C=P_{0} \text {. }
$$

According to Equation (26), we can solve the equilibrium price $\left(P_{0}\right)$ and equilibrium quantity (R0) of restaurant meals. The equilibrium price and quantity $\left(P_{0}\right.$ and $R_{0}$ ) must be economically efficient-that is, given the quantity of restaurant meals produced and sold under market equilibrium, the social planner cannot increase economic well-being by varying the allocation of consumption among consumers or of production among producers. In other words, the equilibrium price $\left(P_{0}\right)$ can maximize the sum of consumer and producer surplus, which means that the equilibrium price $\left(P_{0}\right)$ can maximize social welfare (i.e., economic well-being). (As shown in Figure 1, the sum of consumer and producer surplus $=\Delta a f g$, which is the maximum.)

However, as demonstrated in Figure 1, paying sales taxes in addition to the initial price of the restaurant meal makes consumers less likely to consume restaurant meals. The demand curve shifts from $D_{0}$ to $D_{1}$, and the consumer's utility is reduced from $U_{0}$ to $U_{1}$. Therefore, consumers eventually pay $P_{1}$ (the initial price of the restaurant meal plus the sales taxes) rather than $P_{0}$, as shown below,

$$
\begin{aligned}
D_{1}=S_{0} & \Rightarrow P_{R_{1}}=M C \\
& \Rightarrow \frac{P_{R_{0}}}{1+\tau}=M C \Rightarrow P_{R_{0}}=(1+\tau) M C=P_{1} .
\end{aligned}
$$

Since consumers eventually pay $P_{1}$, and $P_{1}=(1+\tau) M C$. That is, $P_{1} \neq M C$, implying that $P_{1}$ is no longer economically efficient because the price, $P_{1}$, cannot maximize the sum of consumer and producer surplus, indicating that social welfare cannot be maximized. As shown in Figure 1, the sum of consumer and producer surpluses is $\square f b c g$, which is not the maximum and is less than $\Delta a f g$. The difference between $\Delta a f g$ and $\square f b c g$ is $\Delta a b c$, which is the deadweight loss.

Further, as Figure 1 exhibits, consumers who find that they must pay both sales taxes and tips may be less likely to purchase restaurant meals. The demand curve shifts from $D_{0}$ to $D_{2}$, and the consumer's utility is reduced from $U_{0}$ to $U_{2}$. As a result, consumers eventually pay $P_{2}$ (the initial price of the restaurant meal plus the sales taxes and tips) rather than $P_{0}$, as shown below: 


$$
\begin{aligned}
D_{2}=S_{0} & \Rightarrow P_{R_{2}}=M C \\
& \Rightarrow \frac{P_{R_{0}}}{(1+\tau)(1+t)}=M C \Rightarrow P_{R_{0}}=(1+\tau)(1+t) M C=P_{2} .
\end{aligned}
$$

Consumers ultimately pay $P_{2}$, and $P_{2}=(1+\tau)(1+t) M C$. In other words, $P_{2} \neq M C$, inferring that $P_{2}$ cannot be economically efficient. This is because the price, $P_{2}$, cannot maximize the sum of consumer and producer surplus, implying that the price cannot maximize social welfare. As displayed in Figure 1, the sum of consumer and producer surplus becomes $\square$ fdeg, which is not the maximum and is less than $\Delta a f g$. The difference between $\Delta a f g$ and $\square f d e g$ is $\Delta a d e$, which is the deadweight loss and is even larger than the previous deadweight loss $\Delta a b c$. The reason for the increased deadweight loss is that consumers pay tips that creates a substitution effect, which can decrease consumer demand for restaurant meals. According to this demonstration, restaurant tipping does create economic inefficiencies in the restaurant market and thus creates a deadweight loss in the market.

Here, an example may explain why the economic activities of sales taxes and restaurant tipping discourage consumer demand for restaurant meals and create economic inefficiencies in the restaurant market. Assume that a consumer has only $\$ 20$, and that the price of one meal is $\$ 10$. If sales taxes and tips are not required, the consumer may consume two meals. But when present, sales taxes and tips immediately alter consumer behavior. Suppose that the sales tax rate is $10 \%$ and the tipping rate is $20 \%$, and borrowing is not allowed. The consumer now pays $\$ 10$ for the meal, and $\$ 1.00(=\$ 10 \times 10 \%)$ for the tax and $\$ 2.20(=[\$ 10 \times$ $(1 \%+10 \%)] \times 20 \%)$ for the tip, for a total of $\$ 13.20$ for the meal. In other words, the consumer who has only $\$ 20$ and cannot borrow additional funds now cannot consume two meals in the same restaurant.

Based upon this example, the initial equilibrium price $(\$ 10)$ is economically efficient and there is no deadweight loss. Yet, when sales taxes and tips are part of the scenario, the new price ( $\$ 13.20)$ is no longer equal to the marginal cost (because the new price is the initial price $\$ 10$ plus tax [\$1.00] and tip [\$2.20]), and the new quantity is one meal rather than two meals. Consequently, the new price paid by the consumer is no longer economically efficient. Instead, a deadweight loss is created.

In short, restaurant tipping negatively influences consumer demand for restaurant meals, which in turn leads to a substitution effect. The existence of a substitution effect reflects a loss in well-being (i.e., deadweight loss) caused by the substitution effect of a price-distorting tip. In all, both sales taxes and restaurant tipping have the same economic impact in the restaurant market and create a deadweight loss.

\section{Conclusion}

In this research, we used the theory of consumer choice to link restaurant tip- 
ping and consumer behavior. We attempted to determine whether the economic activity of restaurant tipping would lead to economic efficiency or inefficiency in the restaurant market. Our theoretical analysis suggested that restaurant tipping has a negative effect on consumer demand for restaurant meals and thus results in economic inefficiency in the restaurant market. Therefore, our findings may provide some guidelines for the restaurant management. For example, restaurant owners or managers may seek for an alternative way instead of tipping to reward their servers to avoid the occurrence of economic inefficiency. We leave this and related issues for future investigation and discussion.

\section{Conflicts of Interest}

The author declares no conflicts of interest regarding the publication of this paper.

\section{References}

Bodvarsson, O. B., \& Gibbson, W. A. (1994). Gratuities and Customer Appraisal of Service: Evidence from Minnesota Restaurants. The Journal of Socio-Economics, 23, 287-302. https://doi.org/10.1016/1053-5357(94)90005-1

Crusco, A. H., \& Wetzel, C. G. (1984). The Midas Touch: The Effects of Interpersonal Touch on Restaurant Tipping. Personality and Social Psychology Bulletin, 10, 512-517. https://doi.org/10.1177/0146167284104003

Freeman, S., Borden, M. R., \& Latane, B. (1975). Diffusion of Responsibility and Restaurant Tipping: Cheaper by the Bunch. Personality and Social Psychology Bulletin, 1, 584-587. https://doi.org/10.1177/014616727500100407

Lin, T.-C. (2007). Economic Behavior of Restaurant Tipping. Economics Bulletin, 4, 1-10. http://www.accessecon.com/pubs/EB/2007/Volume4/EB-06D00024A.pdf

Lin, T.-C. (2015). Modeling the Relationship between Restaurant Tipping and Consumer Behavior. Theoretical Economics Letters, 5, 389-395.

https://www.scirp.org/pdf/TEL_2015052716150529.pdf https://doi.org/10.4236/tel.2015.53044

Lynn, M. (1988). The Effects of Alcohol Consumption on Restaurant Tipping. Personality and Social Psychology Bulletin, 14, 87-91. https://doi.org/10.1177/0146167288141009

Lynn, M. (2018). How Motivations for Tipping Vary with Occupational Differences in Descriptive Tipping Norms. Journal of Behavioral and Experimental Economics, 77, $1-10$.

https://www.sciencedirect.com/science/article/pii/S2214804318302878?via\%3Dihub https://doi.org/10.1016/j.socec.2018.09.003

Lynn, M., \& Grassman, A. (1990). Restaurant Tipping: An Examination of Three Rational Explanations. Journal of Economic Psychology, 11, 169-181. https://doi.org/10.1016/0167-4870(90)90002-Q

Lynn, M., \& Latane, B. (1984). The Psychology of Restaurant Tipping. Journal of Applied Social Psychology, 14, 549-561. https://doi.org/10.1111/j.1559-1816.1984.tb02259.x

May, J. M. (1978). Tip or Treat: A Study of Factors Affecting Tipping Behavior. Unpublished M.A. Thesis, Chicago, IL: Loyola University of Chicago. 